\title{
Indicator condition-guided HIV testing in Europe: a step forward to HIV control
}

\author{
Francesco Blasi ${ }^{1}$ and Alberto Matteelli²
}

Affiliations: ${ }^{1}$ Dept of Pathophysiology and Transplantation, University of Milan, IRCCS Fondazione Cà Granda Milan, Milan, and ${ }^{2}$ Institute of Infectious and Tropical Diseases, University of Brescia, WHO collaborating centre for TB/HIV collaborative activities, Brescia, Italy.

Correspondence: F. Blasi, Dept of Pathophysiology and Transplantation, University of Milan, IRCCS Fondazione Cà Granda Milan, Italy. E-mail: francesco.blasidunimi.it

0

@ERSpublications

New guidance highlights condition-guided HIV testing

http://ow.ly/mEYku

A new guidance document was published in November 2012 by "HIV in Europe", a pan-European initiative constituted by an independent group of experts with representation from civil society, policymakers, health professionals and European public health institutions. This initiative was started in Brussels in 2007 to promote early diagnosis and earlier care of the HIV infection across Europe. The document, "HIV indicator conditions: guidance for implementing HIV testing in health care settings" is an important step to ensure that people living with HIV enter care earlier in the course of their infection [1]. It was developed by a multidisciplinary panel of experts, because the active commitment of several medical specialties was considered an essential prerequisite for the successful implementation of the recommended approach.

The European Respiratory Society (ERS) has decided to support the initiative and to operate so that its affiliates are part of the project. The ERS recognised early the importance of the synergistic relationship between tuberculosis and HIV and the European Respiratory Journal is on the frontline of the scientific production in this area as certified by recent pivotal publications [2-5]. Now it is time to go beyond.

It is estimated that one in three of the $\sim 2.3$ million HIV-infected individuals living in the European region (i.e. 700,000-900,000 individuals) are unaware of their HIV status [6]. These persons will be diagnosed with HIV infection when the disease becomes symptomatic because of profound immunodeficiency (i.e. with a $\mathrm{CD} 4$ count below 350 cells $\mu \mathrm{L}^{-1}$ ) and will be called "late presenters". Experts believe that a significant proportion of late presenters has been in contact with the healthcare system prior to being diagnosed. Some might have had a sero-conversion illness which remained undiagnosed, others probably presented to one or more health care setting with symptoms caused by diseases associated with immunodeficiency (typically an herpes zoster episode, or oral candidiasis).

An HIV infection which is left untreated because it is undiscovered, will develop in most cases into a full blown AIDS within 12-20 years after the primary infection [7]. If the person is, however, diagnosed and highly active anti-retroviral treatment (HAART) is initiated timely, before severe impairment of the immune system has occurred, life-expectancy may approach that of the general population [8]. Hence, wide access to HIV treatment in Europe has resulted in a situation in which HIV-related morbidity and mortality mainly concerns those who are diagnosed late.

Increased HIV-related morbidity and mortality [9], poorer response to treatment [10] and increased healthcare costs are the consequences of late HIV diagnosis [11]. Moreover, delayed diagnosis is one the most important determinants of increased rates of HIV transmission; based on US modelling data, half of

Received: Nov 062012 | Accepted after revision: Dec 202012

Conflict of interest: None declared.

Copyright @ERS 2013 
new infections are derived from HIV-positive persons that are not yet diagnosed and therefore unaware of the possible risk of transmitting the virus [12].

Therefore, early diagnosis of HIV infection has undisputable benefits and should represent a key public health priority. The current testing strategy for HIV infection mainly targets population groups considered to be at increased risk of infection and relies on the capacity of healthcare providers to counsel and test members of these groups. Clearly, this strategy has proved to be poorly effective in controlling the epidemic in Europe. The reasons for the failure are likely to include a combination of the inability or unwillingness of the clinician to identify and offer tests to at-risk individuals and the inability of affected individuals to consider themselves as being at risk [13].

Innovative approaches are now required to better target testing for individuals who are most likely to be infected with HIV and who would otherwise present late for care. The leading concept of the indicatorguided HIV testing strategy fits into this line. In an indicator condition-guided testing strategy, all patients presenting to any healthcare setting with an "indicator" condition should be routinely offered an HIV test. Evidence exists demonstrating that the offer of an HIV test is pulled up in settings where testing is presented as part of routine care, such as antenatal services and sexual health clinics [8].

In the new guidance document, a number of such "indicator" conditions are grouped into three categories (table 1) [1]. Each category has a different justification for HIV testing and the strength of the recommendation to perform an HIV test also varies according to the category. Category I includes conditions which define AIDS in HIV infected persons (AIDS-defining events). Offering a test in these circumstances has long been considered a good clinical practice because there is a large amount of evidence from randomised controlled trials of the consequences of not treating HIV-positive individuals with AIDSdefining events $[14,15]$. Category II includes conditions associated with a background HIV prevalence of $\geqslant 0.1 \%$. Under these circumstances, routine testing is cost effective [16] and has the potential to shorten the diagnostic delay for HIV. In this category HIV testing is either strongly recommended (clear evidence of a $\geqslant 0.1 \%$ HIV prevalence among persons bearing those conditions) or likely to be recommended ("offer testing", expert opinion that the prevalence of HIV infection among persons bearing those conditions is $\geqslant 0.1 \%)$. Category III includes conditions for which not identifying the presence of HIV infection may have significant adverse implications for the individual's clinical management. Testing should be offered to prevent the worsening of the immunodeficiency and to maximise the response to treatment of the indicator condition. The list of conditions will change as new data are published and will be published on the HIV in Europe website [17].

Some of the conditions listed in table 1 follow under the interest of the pneumology specialty, and are of concern for the members of the ERS, who see, in their clinical practice, patients with these conditions. The offer of an HIV test is a recognised standard of care for all newly diagnosed tuberculosis patients; similarly, individuals being diagnosed with Pneumocystis jirovecii or Cryptococcus neoformans pneumonia are routinely suspected for underlining HIV infection. However, other conditions which are listed in the table probably would not trigger the offer of an HIV test in the current clinical practice. This is the case of recurrent pneumonia and bronchial/lung candidiasis (included in group I conditions) or community-acquired pneumonia and primary lung cancer (included in group II conditions).

The ERS has an important role to play in the promotion of HIV testing as the Society guides the process of adaptation and implementation of the standards of care to be implemented by all affiliated healthcare providers. Training tools can be developed by relevant representatives of the Society in collaboration with colleagues with specific expertise in HIV. Collegial discussions, formal training courses and various forms of encouragement by the ERS leadership would surely contribute towards meeting the targets of the new HIVtesting strategy.

Implementing the strategy will require the management of some crucial issues; although it is recognised that it should be within the competence of any doctor, midwife, nurse or trained healthcare worker to seek consent for an request an HIV test, this is rarely so in clinical practice. In fact, healthcare professionals who are not used to offering HIV tests may feel uncomfortable or have concerns doing so. These concerns should be handled proactively, by promoting open discussions at staff meetings and ensuring access to training and information materials. All healthcare settings planning to implement indicator condition-guided HIV testing should have procedures in place covering practical aspects of test delivery and governance of results. Documented patient care pathways into treatment and care should be agreed with the local HIV services.

Consideration should be given on how to offer the test and seek informed consent. In-depth HIV pre-test counselling is no longer required in the vast majority of individuals; informed consent can be opt-out, meaning that HIV tests will be done routinely unless a patient explicitly refuses to take an HIV test. The offer should be done in an environment which respects the privacy of the person. Most of the information 
TABLE 1 Definitions of indicator conditions and recommendations for HIV testing

Category I

Conditions which are AIDS defining among people living with HIV

Category II

Conditions associated with an
undiagnosed HIV prevalence of
$\geqslant 0.1 \%$

Conditions associated with an $\geqslant 0.1 \%$
Other conditions considered

likely to have an undiagnosed HIV prevalence of $>0.1 \%$
Category III

Conditions for which not identifying

the presence of HIV infection may have significant adverse

implications for the individual's clinical management

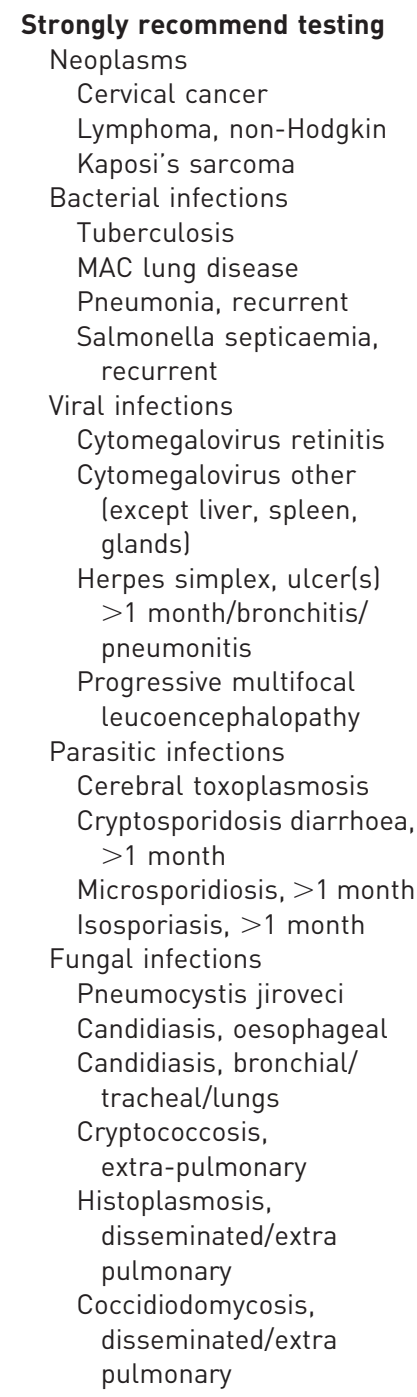

$\begin{array}{cl}\text { Strongly recommend testing } & \text { Offer testing } \\ \text { Sexually transmitted } & \text { Primary lung cancer } \\ \text { infections } & \text { Lymphocytic meningitis } \\ \text { Malignant lymphoma } & \text { Visceral leishmaniasis } \\ \text { Anal cancer/dysplasia } & \text { Hairy leukoplakia } \\ \text { Cervical dysplasia } & \text { Severe or recalcitrant psoriasis } \\ \text { Herpes zoster } & \text { Guillain-Barré syndrome } \\ \text { Hepatitis B or C lacute or } & \text { Mononeuritis } \\ \text { chronicl } & \text { Subcortical dementia } \\ \text { Mononucleosis-like illness } & \text { Multiplesclerosis-like disease } \\ \text { Unexplained leukocytopenia/ } & \text { Peripheral neuropathy } \\ \text { thrombocytopenia lasting } & \text { Unexplained weight loss } \\ >4 \text { weeks } & \text { Unexplained lymphadenopathy } \\ \text { Seborrhoeic dermatitis/ } & \text { Unexplained oral candidiasis } \\ \text { exanthema } & \text { Unexplained chronic diarrhoea } \\ \text { Invasive pneumococcal disease } & \text { Unexplained chronic renal } \\ \text { Fever of unknown origin } & \text { impairment }\end{array}$

Non-genital Candidiasis

Community-acquired pneumonia

Nosocomial diarrhoea

Pregnancy (implications for the unborn child)

\section{Offer testing}

Conditions requiring aggressive immuno-suppressive therapy Cancer

Transplantation

Auto-immune disease treated with immunosuppressive therapy

Primary space occupying lesion of the brain

Thrombotic thrombocytopenic purpura?

concerning HIV infection and its consequences might be given in written form, which the individual can retain. The pre-test discussion should include the opportunity for questions the patient may have. The approach to the post-test discussion and the level of detailed counselling depends on the test results. If the HIV test is negative, written material or directions to where the person can seek additional information can be provided to persons interested in knowing more about HIV. If the HIV test is positive, it is imperative that the healthcare setting has clear written policies on how to handle such a situation. ERS members are welcome to contact the HIV in Europe Secretariat, who coordinated the development of the guidance and its implementation, should any specific question arise.

In summary, ERS endorses the introduction of the strategy for HIV testing based on indicator conditions triggering and takes part to the overall efforts to extend HIV testing to a wide variety of healthcare settings. The Society solicits the discussion on the most appropriate ways to disseminate into the clinical practice the offer of an HIV test for specific pneumological conditions which include community-acquired pneumonia, 
recurrent pneumonia and primary lung cancer. The ERS also actively engages in the production and dissemination to its members of quality assurance and quality improvement protocols, which are required to ensure that testing is delivered in a standard, efficient and ethical manner and that it is tailored to sitespecific needs. Finally, the Society is ready to provide its contribution to the process of making testing a routine component of medical care that will contribute to current efforts to de-stigmatise HIV and HIV testing.

\section{References}

1 HIV in Europe. Guidance document: HIV Indicator Conditions: Guidance for implementing HIV testing in adults in health care settings. Available from: www.hiveurope.eu/LinkClick.aspx?fileticket $=$ b8rDoBh $8 \mathrm{NjM}=8 \mathrm{tabid}=37$ Date last accessed: July 3, 2013.

2 Kruijshaar ME, Pimpin L, Abubakar I, et al. The burden of TB-HIV in the EU: how much do we know? A survey of surveillance practices and results. Eur Respir J 2011; 38: 1374-1381.

3 Pimpin L, Drumright LN, Kruijshaar ME. Tuberculosis and HIV co-infection in European Union and European Economic Area countries. Eur Respir J 2011; 38: 1382-1392.

4 Lapadula G, Soria A, Bandera A, et al. Unmasking tuberculosis in the era of antiretroviral treatment. Eur Respir $J$ 2012; 39: 1064-1075.

5 Schutz C, Meintjes G, Almajid F, et al. Clinical management of tuberculosis and HIV-1 co-infection. Eur Respir J 2010; 36: 1460-1481.

6 ECDC. HIV/AIDS surveillance in Europe 2010. www.ecdc.europa.eu/en/publications/publications/111129_sur_ annual_hiv_report.pdf Date last accessed: July 3, 2013.

7 Bartlett JG, Gallant JE. Medical management of HIV infection. Baltimore, Johns Hopkins Medicine Health Publishing Business Group, 2007.

8 Baggaley R. HIV for non-HIV specialists, diagnosing the undiagnosed. 2008. Available from www.medfash.org.uk/ uploads/files/p17am0h8v510dr1f941ebg1sicgpr.pdf Date last accessed: July 3, 2013.

9 Nakagawa F, Lodwick RK, Smith CJ, et al. Projected life expectancy of people with HIV according to timing of diagnosis. AIDS 2012; 26: 335-343.

10 Lanoy E, Mary-Krause M, Tattevin P, et al. Frequency, determinants and consequences of delayed access to care for HIV infection in France. Antiviral Ther 2007; 12: 89-96.

11 Schackman BR, Freedberg KA, Weinstein MC, et al. Cost-effectiveness implications of the timing of antiretroviral therapy in HIV-infected adults. Arch Intern Med 2002; 162: 2478-2486.

12 Hall HI, Holtgrave DR, Maulsby C. HIV transmission rates from persons living with HIV who are aware and unaware of their infection, United States. AIDS 2012; 26: 893-896.

13 Chen JY, Tian H, Dahlin-Lee E, et al. HIV Testing and Monitoring in Privately Insured Members Recently Diagnosed with Potential AIDS Defining Events, CROI, 2009, poster 1044.

14 Mocroft A, Vella S, Benfield TL, et al. Changing patterns of mortality across Europe in patients infected with HIV-1. EuroSIDA Study Group. Lancet 1998; 352: 1725-1730.

15 Palella FJ Jr, Delaney KM, Moorman AC, et al. Declining morbidity and mortality among patients with advanced human immunodeficiency virus infection. HIV Outpatient Study Investigators. N Engl J Med 1998; 338: 853-860.

16 Yazdanpanah Y, Sloan CE, Charlois-Ou C, et al. Routine HIV screening in France: clinical impact and costeffectiveness. PLoS One 2010; 5: e13132.

17 HIV in Europe. www.hiveurope.eu Date last accessed: July 3, 2013. 